\title{
Modulation of Neurotransmitter Receptor Desensitization: Chlordiazepoxide Stimulates Fading of the GABA Response
}

\author{
Daniel Mierlak and David H. Farb \\ Department of Anatomy and Cell Biology, The State University of New York, Health Science Center at Brooklyn, Brooklyn, \\ New York 11203
}

\begin{abstract}
Benzodiazepines are neuromodulatory drugs that potentiate GABA-mediated conductance increases. We report the findings of an investigation into the effect of a full benzodiazepine-positive modulator (agonist), chlordiazepoxide (CDPX), on desensitization of the GABA response in chick spinal cord neurons maintained in primary monolayer cell culture. GABA application initially increases cell conductance, which then desensitizes. CDPX increases the apparent rate constant and extent of desensitization for the GABA response. The observed values for rate constant and extent of desensitization in the presence of CDPX are significantly greater than the values predicted for an equivalent peak response to GABA alone. Flunitrazepam, another full positive modulator, also stimulates the rate constant for GABA-induced desensitization. Furthermore, a weak partial benzodiazepine-positive modulator, Ro15-1788 (an imidazodiazepine) (1) exhibits little or no potentiation of GABA-induced desensitization, and (2) antagonizes the ability of CDPX to stimulate GABA desensitization. The results demonstrate a novel form of neuromodulator action: the stimulation of receptor desensitization that cannot be explained by channel blockade. Thus, benzodiazepine modulators have the capacity to increase GABA receptor desensitization while increasing the peak response to GABA.
\end{abstract}

The cellular response of many receptor systems fades, or desensitizes, upon continued exposure to receptor agonists. Whereas the phenomenon of desensitization to agents such as neurotransmitters, hormones, chemotactic agents, and drugs is well known (Levitzki, 1986), its biological function remains unclear, particularly for neurotransmitter receptors that are coupled to ion channels. At many chemical synapses, synaptic potentials last several milliseconds, while desensitization takes seconds to minutes. It is not yet known whether desensitization may serve to regulate neural responses that involve persistent synaptic activity.

GABA, a major inhibitory neurotransmitter in the vertebrate CNS, exerts its action by selectively increasing membrane chloride permeability. The GABA receptor-chloride ionophore complex has emerged as a locus of action for a wide variety of

Received May 15, 1987; revised Aug. 10, 1987; accepted Aug. 26, 1987

We thank Dr. Terrell Gibbs and Dr. Grant Schiller for stimulating discussions, and Ms. Inna Rozenburg for technical assistance. We are especially grateful to Dr. Thomas Easton for development of the computer system. This work was supported by NIH Grant R01-NS-22116.

Correspondence should be addressed to Dr. Farb at the above address.

Copyright 1988 Society for Neuroscience 0270-6474/88/030814-07\$02.00/0 compounds, reflecting the unique capacity of this system to be diversely modulated (Olsen, 1982). The past decade has been a period of intense investigation into the mechanism by which benzodiazepine drugs interact with the GABA receptor complex (Costa et al., 1975; Haefely, 1984). Electrophysiological studies have focused primarily on the observation that benzodiazepines potentiate GABA-mediated conductance increases (Choi et al., 1977; Study and Barker, 1981) through the benzodiazepinesensitive modulator site (Farb et al., 1984). However, little is known of benzodiazepine interactions with the process of GABA receptor desensitization. Here we report the results of an invcstigation into the effect of a benzodiazepine, chlordiazepoxide (CDPX), on desensitization of the GABA response in embryonic chick spinal cord cell cultures. We find that CDPX stimulates the rate and extent of GABA receptor desensitization over and above the level predicted for an equivalent GABA response in the absence of CDPX. Furthermore, the imidazodiazepine Ro151788, a weak partial agonist of the benzodiazepine receptor, antagonizes the CDPX-stimulated desensitization. A preliminary report of this work has been presented (Mierlak and Farb, 1985).

\section{Materials and Methods}

Benzodiazepines were generously provided by Dr. P. Sorter of F. Hoffman-La Roche (Nutley, NJ). All other chemicals were obtained from commercial sources.

Neuronal cultures were prepared from spinal cords of 6-7-d-old chick embryos as previously described (Farb et al., 1979) and maintained for 2-5 weeks. Electrophysiological experiments were performed on the stage of an inverted microscope equipped with phase-contrast optics. Cultures were kept at $35-37^{\circ} \mathrm{C}$ and perfused $(1 \mathrm{ml} / \mathrm{min}$, bath volume 2-3 ml) with recording medium at pH 7.4 (Earle's balanced salts solution supplemented with $2.2 \mathrm{mM} \mathrm{CaCl}_{2}, 16 \mathrm{mM}$ glucose, $0.25 \%$ horse serum, and either $9.2 \mathrm{~mm} \mathrm{MgSO}_{4}$ or $50 \mathrm{~nm}$ tetrodotoxin to suppress spontaneous activity). Recordings were obtained with $3 \mathrm{M} \mathrm{KCl,} 4$ м potassium acetate (KAc), or $0.5 \mathrm{M} \mathrm{KAc}$ electrodes $(R=30-80 \mathrm{M} \Omega)$ under singleelectrode current-clamp conditions.

Membrane conductance $\left(g_{\mathrm{m}}\right)$ was determined from Ohm's Law after measuring the voltage response to hyperpolarizing constant-current pulses $(100 \mathrm{msec}, 1 \mathrm{~Hz}, 0.2-1.2 \mathrm{nA})$ injected across the membrane by means of a bridge circuit. Cells that did not exhibit a resting potential of at least $-50 \mathrm{mV}$, a linear current-voltage relationship (Fig. 1), and unambiguous bridge balance were excluded from study. Occasionally, some neurons exhibited GABA responses that were not potentiated by CDPX; these neurons were not studied. Conductance observed in the presence of GABA ( $g_{\text {obs }}$ ) was corrected by subtracting $g_{\mathrm{m}}$ to yield conductance due to GABA $\left(g_{\mathrm{GABA}}\right)$. Voltage responses to current injection were measured from the chart recorder traces or by computer.

Water-soluble drugs were dissolved in recording medium without horse serum and applied to single neurons by pressure-ejection from 7-barrel blunt-tip pipettes (3-5 $\mu \mathrm{m} /$ barrel). Water-insoluble drugs were first dissolved in dimethyl sulfoxide and then diluted in recording medium without horse serum to a final concentration of $0.2 \%$ dimethyl 



Figure 1. High-speed oscilloscope records from 2 neurons showing electrotonic potentials in response to hyperpolarizing current injections. $\mathrm{A}, \mathrm{KCl}$ electrode (3 M). Upper record, current pulses of 0 to $-0.5 \mathrm{nA}$ at $0.1 \mathrm{nA}$ intervals; duration, $100 \mathrm{msec}$. Lower record, linear steady-state voltage responses over the current range without significant anomalous rectification. $B$, KAc electrode $(0.5 \mathrm{M})$. Records as in $A$, except 0 to $-0.3 \mathrm{nA}$ range; duration, $60 \mathrm{msec}$. For both cells, each current pulse was applied 3 times. Resting potentials, $-75 \mathrm{mV}(A),-57 \mathrm{mV}(B)$. sulfoxide, which did not in itself affect membrane potential or conductance. Statistical significance was assessed using a 2-tailed Student's $t$ test.

Two parameters were chosen for quantitation of GABA receptor desensitization: the extent of desensitization $(\% D)$ and the apparent rate constant for onset of desensitization $\left(k_{\mathrm{app}}\right)$. The conductance increase in response to pressure-ejection of GABA reaches a peak (peak $g_{\mathrm{GABA}}$ ) and then desensitizes to a steady-state level $\left(g_{\mathrm{ss}}\right)$. Extent of desensitization $(\% D)$ was defined as [(peak $\left.g_{\mathrm{GABA}}-g_{\mathrm{SS}}\right) /$ peak $\left.g_{\mathrm{GABA}}\right] \times 100 \%$. To evaluate $k_{\mathrm{app}}$, the value of $g_{\mathrm{ss}}$ was subtracted from $g_{\mathrm{GABA}}$ values comprising the first $80 \%$ of decay; $\left(g_{\mathrm{GABA}}-g_{\mathrm{Ss}}\right)$ was then plotted semilogarithmically against time. The best straight line was used to determine $k_{\text {app }}$ as follows: $k_{\mathrm{app}}=0.693 / t_{1 / 2}$, where $t_{t_{1 / 2}}$ is the time required for any $\left(g_{\mathrm{GABA}}-g_{\mathrm{ss}}\right)$ value to decay by $50 \%$. In some experiments, $k_{\text {app }}$ was determined by a nonlinear-regression curve-fitting program. Occasionally, nonlinear-regression analysis favored a double-exponential decay. In such cases, the rate constant for the initial, fast phase was used for analysis.

The value of $\% D$ depends on measurement of the peak response, as well as on the steady-state level of desensitization. For the results presented, the largest $g_{\text {GABA }}$ value measured after the start of GABA application was taken as the peak response. However, the time required to reach the peak response is variable (generally between 1 and $5 \mathrm{sec}$ ). It is possible that the peak response measured for cells that display a longer time to reach peak represents an underestimate of the "true" peak response, since desensitization is presumably taking place during the rising phase of the response. In these cases $\% D$ may also be under- 
Figure 2. Desensitization of the response to $10 \mu \mathrm{M}$ GABA. $A$, Slow-speed chart record from a neuron impaled with a $3 \mathrm{~m} \mathrm{KCl}$ electrode. The downward transients represent voltage responses to hyperpolarizing constant-current pulses $(0.8 \mathrm{nA})$. GABA $(10 \mu \mathrm{M})$ was applied continuously for the time indicated by the bar below record (time scale in $B$ ). Membrane potential, $-45 \mathrm{mV}$. $B$. Time course of desensitization from the trace in $A . g_{\mathrm{GABA}}$ was calculated (see Materials and Methods) and plotted against time. $g_{\mathrm{GABA}}$ reaches a peak (64 $\mathrm{nS})$ and then desensitizes to a steadystate level $\left(g_{\text {ss }}=24 \mathrm{nS}\right) . \% D$, calculated as described in Materials and Methods, is $62 \%$. $C$, Determination of $k_{\mathrm{app}} \cdot g_{\mathrm{GABA}}$ values are corrected by subtracting $g_{\text {ss }}$ and then plotted semilogarithmically against time. For this cell, $t_{1 /,}=11.2 \mathrm{sec}$, $k_{\text {app }}=0.062 \mathrm{sec}^{-1}$.

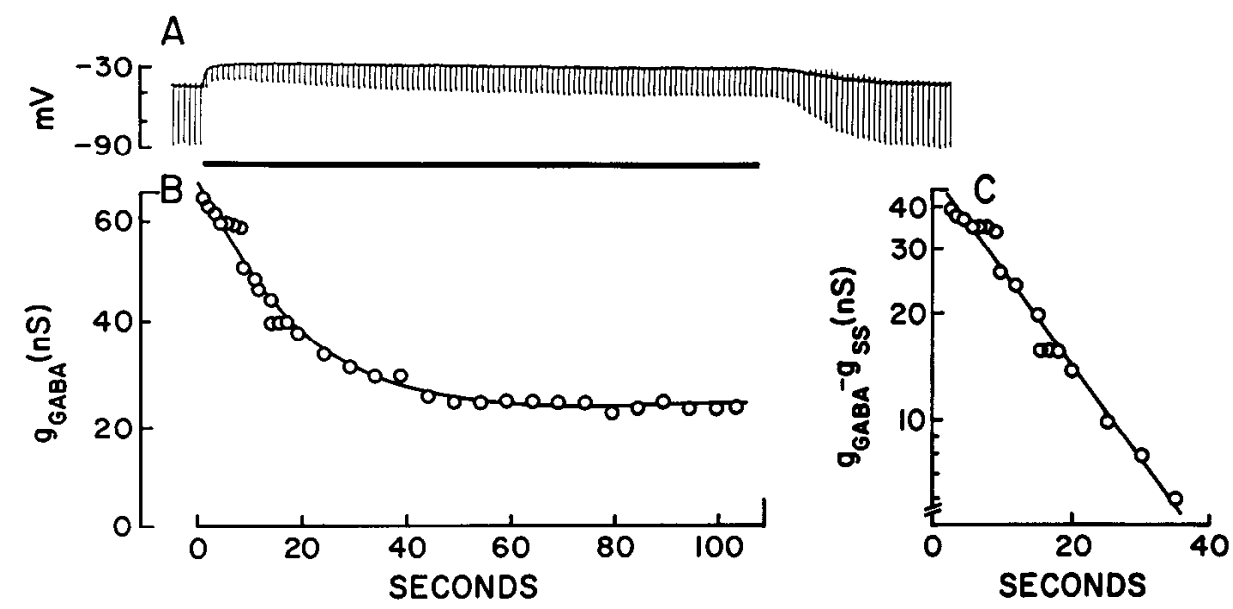

estimated. Evaluation of the true peak response may be standardized by back-extrapolating desensitization-onset plots to time zero (onset of GABA application) and using this extrapolated value to determine $\% D$. However, this would lead to an overestimate of peak response and $\% D$, since it clearly takes some period of time for the drug solution to be expelled from the pipette tip, to displace the surrounding bathing medium, to diffuse to, and to interact with, the receptors. It seems certain that the "true" peak response and $\% D$ lie within the range defined by the 2 methods of analysis. Both methods of calculation of peak response and $\% D$ were employed and the results compared. Although, as expected, the values for peak response and $\% D$ increased when calculated by back-extrapolation, importantly, the conclusions drawn from the use of these values were independent of the method of analysis.

The use of $\mathrm{KCl}$ recording electrodes results in an increased intracellular chloride ion concentration, which shifts the reversal potential for chloride to about $-20 \mathrm{mV}$. Application of GABA, which increases chloride conductance, then produces a depolarization. To ensure that the results obtained with $\mathrm{KCl}$ electrodes were not dependent on depolarization, we recorded from neurons with KAc electrodes. These electrodes do not alter the intracellular chloride ion concentration. Under these conditions, GABA induces a smaller depolarization, which could often be minimized by depolarizing the cell with a small, constant, positive current before applying GABA.

\section{Results}

Desensitization of the response to $G A B A$

Every spinal cord neuron successfully impaled is responsive to GABA, although the degree of responsiveness is variable from cell to cell. For most cells, the conductance increase induced by $10 \mu \mathrm{M}$ GABA $\left(\mathrm{EC}_{50}=17 \mu \mathrm{M}\right)$ desensitizes upon prolonged application (Fig. 2). Recovery from desensitization is complete within 3-4 min for $10 \mu \mathrm{M}$ GABA. In a sample of 19 neurons impalcd with $3 \mathrm{M} \mathrm{KCl}$ electrodes and exposed to $10 \mu \mathrm{M}$ GABA, $\% D$ is $72 \pm 2 \%$ and $k_{\text {app }}$ is $0.069 \pm 0.006 \mathrm{sec}^{-1}$ (means $\pm \mathrm{SEM}$;

Table 1. Comparison of $k_{\text {app }}$ and \%D for $10 \mu \mathrm{M} \mathrm{GABA}$ under $\mathrm{KCl}$ and $\mathrm{KAC}$ recording conditions

\begin{tabular}{llll} 
Condition & $k_{\text {app }}\left(\mathrm{sec}^{-1}\right)$ & $\% D$ & $\begin{array}{l}\text { No. of } \\
\text { neurons }\end{array}$ \\
\hline $10 \mu \mathrm{M}$ GABA, $\mathrm{KCl}$ electrodes & $0.069 \pm 0.006$ & $72 \pm 2$ & 19 \\
$10 \mu \mathrm{M}$ GABA, KAc electrodes & $0.074 \pm 0.005$ & $63 \pm 2^{*}$ & 58
\end{tabular}

$k_{\text {app }}$ and $\% D$ were calculated as described in Materials and Methods.

* Significantly different $(p<0.005)$ from $\% D$ with $\mathrm{KCl}$ electrodes.
Table 1). Depolarizations of $20-30 \mathrm{mV}$ are generally seen with $10 \mu \mathrm{M}$ GABA applications.

To control for the depolarization seen with $\mathrm{KCl}$ recording electrodes (see Materials and Methods), we applied $10 \mu \mathrm{M}$ GABA to neurons impaled with KAc electrodes. Under these conditions, depolarization rarely exceeds $10 \mathrm{mV}$ and, in many cases, application of GABA causes no change in potential or a hyperpolarization. For 58 neurons impaled with KAc electrodes and exposed to $10 \mu \mathrm{M}$ GABA, $\% D$ is $63 \pm 2 \%$ and $k_{\text {app }}$ is $0.074 \pm$ $0.005 \mathrm{sec}^{-1}$ (means \pm SEM; Table 1 ).

\section{Dependence of $\% \mathrm{D}$ and $\mathbf{k}_{a p p}$ on $G A B A$ concentration}

To investigate the relationship between GABA concentration and both $\% D$ and $k_{\text {app }}$, several different concentrations of GABA were applied to individual neurons. $\% D$ increases with increasing GABA concentration (18 neurons) using $\mathrm{KCl}$ or $\mathrm{KAc}$ recording electrodes. For $\mathrm{KCl}$ electrodes, plots of $\% D$ against peak response to GABA (10-22 $\mu \mathrm{M})$ are linear. Using KAc electrodes, such plots are either linear or curvilinear over a wide range of GABA concentrations (10-300 $\mu \mathrm{M}) . k_{\text {app }}$ also increases with increasing GABA concentration (19 neurons). Plots of $k_{\mathrm{app}}$ against peak response are linear, using both $\mathrm{KCl}$ and $\mathrm{KAc}$ electrodes.

\section{Effect of CDPX on desensitization}

CDPX, a water-soluble benzodiazepine, was tested for its effect on desensitization of the GABA response. In the presence of near-saturating CDPX $\left(200-430 \mu \mathrm{M} ; \mathrm{EC}_{50}=17 \mu \mathrm{M}\right)$, the peak response to $10 \mu \mathrm{M}$ GABA (peak $g_{\mathrm{GABA}}{ }^{\prime}$ ) is potentiated and both $\% D$ and $k_{\text {app }}$ increase (Fig. 3). In 11 neurons impaled with $\mathrm{KCl}$ electrodes, the presence of $300 \mu \mathrm{M}$ CDPX increased $\% D$ by $29 \%$ out of a theoretical maximum of $37 \%$ (Table 2). The value of $k_{\mathrm{app}}$ in the presence of $\operatorname{CDPX}\left(k_{\mathrm{app}}{ }^{\prime}\right)$ is 3.7 -fold greater than that of $k_{\text {app }}$ for GABA alone (Table 2). Twenty-four neurons impaled with KAc electrodes demonstrated a similar significant increase in $\% D$ and $k_{\text {app }}$ in the presence of CDPX $(200-430 \mu \mathrm{M})$.

The ability to accelerate desensitization is not limited to CDPX. Flunitrazepam $\left(0.5-2 \mu \mathrm{M} ; \mathrm{EC}_{50}=180 \mathrm{nM}\right)$, another full benzodiazepine agonist, was found to accelerate GABA $(10 \mu \mathrm{M})$ induced desensitization in 6 out of 6 neurons impaled with KAc electrodes. $k_{\text {app }}$ increased $2.9 \pm 0.8$-fold in the presence of flunitrazepam, as compared with an average increase of $3.1 \pm 0.6-$ 


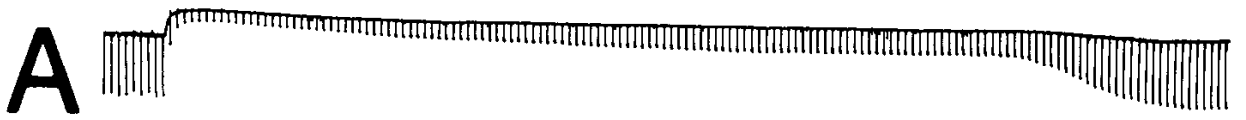

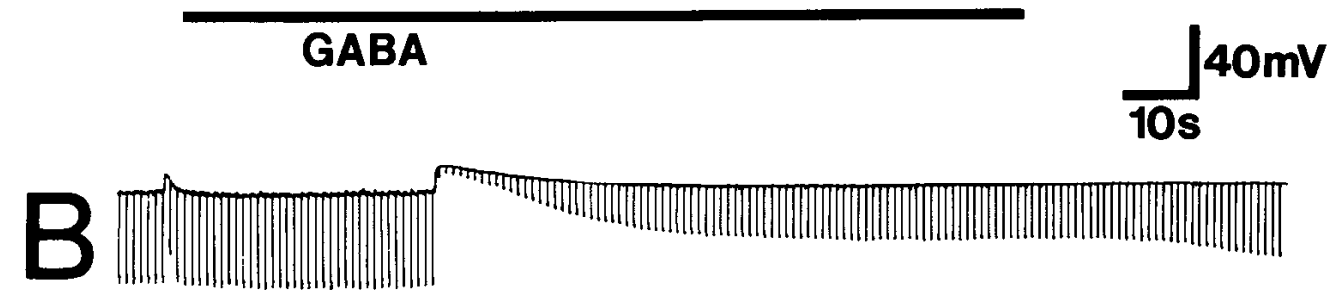

\section{CDPX GABA+ CDPX}

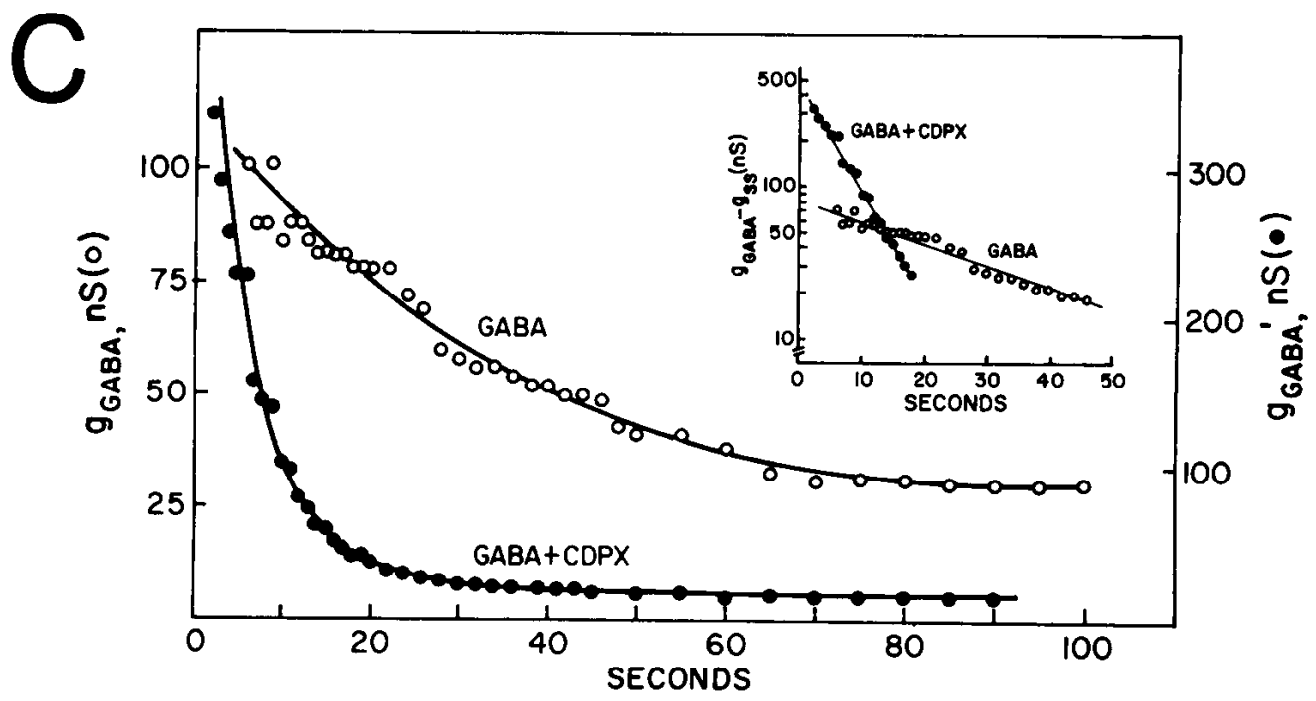

Figure 3. CDPX increases $\% D$ and $k_{\mathrm{app}}$. Records from a single neuron show the response to $10 \mu \mathrm{M}$ GABA alone $(A)$ and in the presence of $300 \mu \mathrm{M}$ CDPX $(B)$. The GABA + CDPX pulse is preceded by a $30 \mathrm{sec}$ prepulse of CDPX alone, which does not affect membrane potential or conductance. Constantcurrent pulses: $A, 0.6 \mathrm{nA} ; B, 1.0 \mathrm{nA}$. Membrane potential, $-56 \mathrm{mV}$. Electrode, $3 \mathrm{~m} \mathrm{KCl}$. $C$, Time course for desensitization to $10 \mu \mathrm{M}$ GABA alone $\left(g_{\mathrm{GABA}}, O\right)$ and in the presence of 300 $\mu \mathrm{M}$ CDPX $\left(g_{\mathrm{GABA}}, \theta\right)$ (note different ordinates). CDPX potentiates peak $g_{G A B A}$ and enhances $\% D$ from 70 to $96 \%$. Inset, Semilogarithmic plot of data. The presence of CDPX increases $k_{\text {app }}$ from 0.035 to $0.154 \mathrm{sec}^{-1}$, representing a $4.4-$ fold increase. fold in the presence of CDPX under similar recording conditions.

Given the potentiation of peak $g_{\mathrm{GABA}}$ by CDPX, it is important to determine whether this increase in peak response can account for the enhancement of $\% D$ and $k_{\text {app }}$ seen in the presence of CDPX. A series of GABA concentrations was applied to individual neurons impaled with $\mathrm{KCl}$ electrodes, and then $10 \mu \mathrm{M}$ GABA plus $300 \mu \mathrm{M}$ CDPX was applied. Since the plots of both $\% D$ and $k_{\text {app }}$ against peak $g_{\mathrm{GABA}}$ were linear over the GABA range used, it was possible to compare the observed values for the apparent rate constant $\left(k_{\text {app }}{ }^{\prime}\right)$ and $\% D$ in the presence of CDPX with the corresponding values for an equivalent peak GABA response in the absence of CDPX. In 5 of 6 neurons, the observed values for both $k_{\mathrm{app}}{ }^{\prime}$ and \%D in the presence of CDPX were greater than those predicted for equivalent peak $g_{\mathrm{GABA}}$ values elicited by GABA alone (Figs. 4, 5). A $19 \%$ increase in $\% D$ was predicted from CDPX potentiation of peak $g_{\mathrm{GABA}}$; however, a $36 \%$ increase was observed. For $k_{\text {app }}$, a 1.8 -fold increase was predicted, but a 3.6-fold increase was observed with CDPX.

Results from 9 neurons impaled with KAc electrodes corroborated the $\mathrm{KCl}$ findings. CDPX enhanced $\% D$ over predicted levels in 8 of 9 neurons, while $k_{\text {app }}$ was enhanced in 7 of 9 neurons. In these experiments, depolarization upon GABA ap- plication was usually under $5 \mathrm{mV}$ (maximum, $8 \mathrm{mV}$ ). The degree of enhancement over predicted levels was similar to that seen for $\mathrm{KCl}$ recordings.

\section{Ro15-1788 antagonizes CDPX-stimulated desensitization}

To verify that the enhancement of $\% D$ and $k_{\mathrm{app}}$ seen in the presence of CDPX was mediated through the benzodiazepine receptor, experiments were performed with Ro15-1788, an imidazodiazepine that behaves as a weak partial agonist in its

$\begin{aligned} & \text { Table 2. Desensitization of the response to } 10 \mu \mathrm{M} \text { GABA in the } \\
& \text { presence and absence of CDPX }\end{aligned}$
\begin{tabular}{llc} 
Condition & $k_{\mathrm{app}}\left(\mathrm{sec}^{-1}\right)$ & $\% D$ \\
\hline $10 \mu \mathrm{M}$ GABA & $0.061 \pm 0.006$ & $73 \pm 3$ \\
$10 \mu \mathrm{M}$ GABA $+300 \mu \mathrm{M}$ CDPX & $0.224 \pm 0.023^{*}$ & $94 \pm 0.9^{*}$ \\
Theoretical maximum & - & 100
\end{tabular}

$\overline{\text { Summary of results from } 11 \text { neurons, } \mathrm{KCl} \text { electrodes. } k_{\mathrm{app}} \text { and } \% D \text {, calculated as }}$ described in Materials and Methods, are means \pm SEM. $k_{\text {app }}$ increases 3.7-fold in the presence of CDPX. $\% D$ increases by $29 \%$ with CDPX [i $-(94 / 73) \times 100 \%]$; however, the maximal increase possible is only $37 \%[1-(100 / 73) \times 100 \%]$.

* Significantly different $(p<0.001)$ from $10 \mu \mathrm{M}$ GABA alone. 


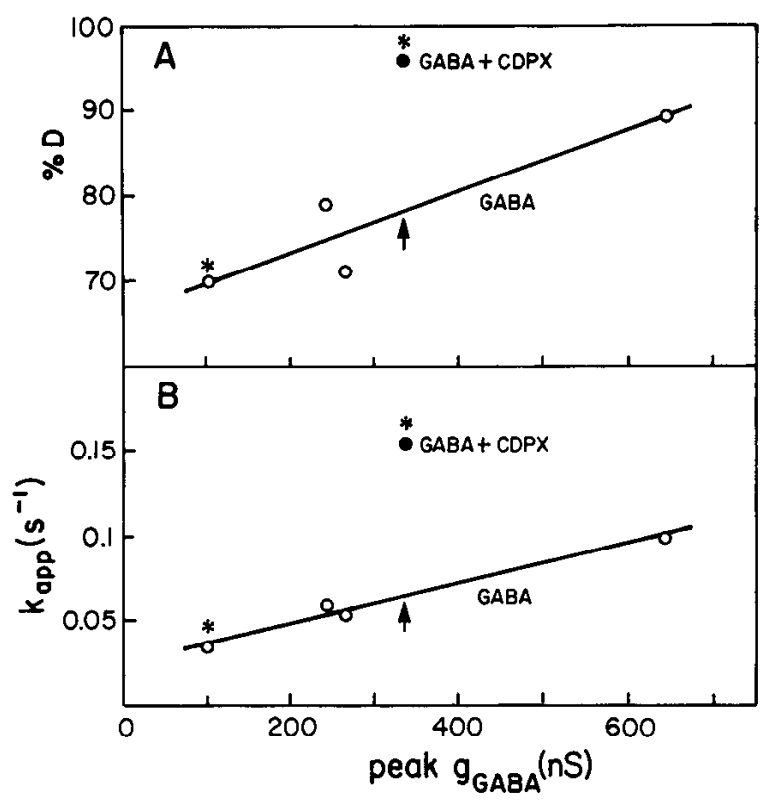

Figure 4. Experiment on a single neuron showing that CDPX enhances $\% D$ and $k_{\text {app }}$ over the corresponding values for an equivalent GABA response. $A$, Plot of $\% D$ against peak response for 4 different GABA concentrations (open circles: 10, 14, 18, $22 \mu \mathrm{M}$ ) applied to the neuron from Figure 3. Asterisks mark $10 \mu \mathrm{M} \mathrm{GABA}$ alone $(\mathrm{O})$ and in the presence of $300 \mu \mathrm{M}$ CDPX (O). A $96 \%$ desensitization is observed with CDPX (ब), although only $78 \%$ is predicted for an equivalent GABA response (arrow). B. Plot of $k_{\mathrm{app}}$ against peak response in the same cell. $k_{\mathrm{app}}$ ' for $10 \mu \mathrm{M}$ GABA $+300 \mu \mathrm{M}$ CDPX is $0.154 \mathrm{sec}^{-1}(\mathbf{0})$, although only 0.064 $\mathrm{sec}^{-1}$ is predicted (arrow).

ability to potentiate $g_{\text {GABA }}$ (Chan and Farb, 1985). Ro15-1788, when applied at saturating concentrations (1-2 $\mu \mathrm{M})$ with $10 \mu \mathrm{M}$ GABA, had little effect on $\% D$ and $k_{\text {app }}$ compared to control values for $10 \mu \mathrm{M}$ GABA alone [in the presence of Ro15-1788, $k_{\text {app }}$ increased 1.2-fold $(p>0.1) ; \% D$ increased $11 \%$ out of a maximum 39\% ( $p<0.025)$; $n=5$ neurons, $\mathrm{KCl}$ electrodes]. The interaction of Rol5-1788 with CDPX was tested in 2 cells as follows: A $30 \mathrm{sec}$ prepulse of $2 \mu \mathrm{M}$ Rol5-1788 was followed by a $10 \mathrm{sec}$ pulse of $2 \mu \mathrm{M}$ Ro $15-1788$ plus $300 \mu \mathrm{M}$ CDPX, after which $10 \mu \mathrm{M}$ GABA, $2 \mu \mathrm{M}$ Ro15-1788, and $300 \mu \mathrm{M}$ CDPX were applied. In both cells, the enhancement of $\% D$ and $k_{\text {app }}$ by CDPX (compared to control $10 \mu \mathrm{M}$ GABA values) was reduced by about 40 and 50\%, respectively, when CDPX was applied in the presence of Rol 5-1788 (Fig. 6). The antagonism by Ro15-1788 was expected to be partial, since both Ro15-1788 and CDPX were competing for the benzodiazepine site at saturating concentrations.

\section{Discussion}

The phenomenon of receptor desensitization may be viewed as a modulatory responsc of the cell to acutc, persistent activation of a receptor system. But there is, at present, no comprehensive model that satisfactorily explains neurotransmitter receptor desensitization either mechanistically or teleologically. It is, therefore, impossible to predict for the GABA receptor whether and how modulatory agents might alter GABA desensitization.

The main conclusions of this study relate to the control of GABA receptor desensitization by benzodiazepine neuromodulators. The ability of benzodiazepines to potentiate GABA chemosensitivity has been well established in electrophysiological studies (Choi et al., 1977, 1981; Study and Barker, 1981). Notably, CDPX has been shown to shift the GABA dose-response curve to the left in a parallel fashion (Choi et al., 1981), suggesting that potentiation in the presence of CDPX is due to an increase in the affinity of the GABA receptor for GABA. The benzodiazepines might be expected to enhance desensitization of GABA responses by virtue of this increase in GABA receptor affinity. Alternatively, GABA desensitization might not be triggered by chloride channel activity, but might, rather, result from the binding of GABA to a distinct site. In this model, the benzodiazepine neuromodulators could either increase desensitization more than is predicted from the peak response to GABA, exert no effect upon desensitization, or even inhibit desensitization.

Here we demonstrate directly that a benzodiazepine, CDPX, stimulates the rate and extent of desensitization produced in response to $10 \mu \mathrm{M}$ GABA. Surprisingly, CDPX stimulates desensitization more than is predicted from the degree of potentiation produced. Thus, stimulation does not simply reflect
Figure 5. Pooled data showing that CDPX stımulates GABA-induced desensitization. $A, k_{\text {app }}$ for $10 \mu \mathrm{M}$ GABA (open bar) increases 3.6-fold in the presence of $300 \mu \mathrm{M}$ CDPX (solid bar). The hatched bar represents the predicted value of $k_{\text {app }}$ for a GABA pulse alone with a peak response equivalent to $10 \mu \mathrm{M} \mathrm{GABA}+300 \mu \mathrm{M}$ CDPX. The predicted increase in $k_{\text {app }}$ is only 1.8fold. $R, \% D$ for $10 \mu \mathrm{M}$ GABA (open har) increases by $36 \%$ when $300 \mu \mathrm{M}$ CDPX is present (solid bar). The hatched bar represents the predicted value of $\% D$ for a GABA pulse alone with a peak response equivalent to GABA + CDPX. The predicted increase in $\% D$ is only $19 \%$. The stippled bar is the maximum $\% D$ possible, corresponding to a $45 \%$ incrcasc over $10 \mu \mathrm{M}$ GABA alonc. Data are means $\pm \mathrm{SEM}$; 5 neurons; $\mathrm{KCl}$ electrodes. *Significantly different: $A, p<$ $0.005 ; B, p<0.05$.
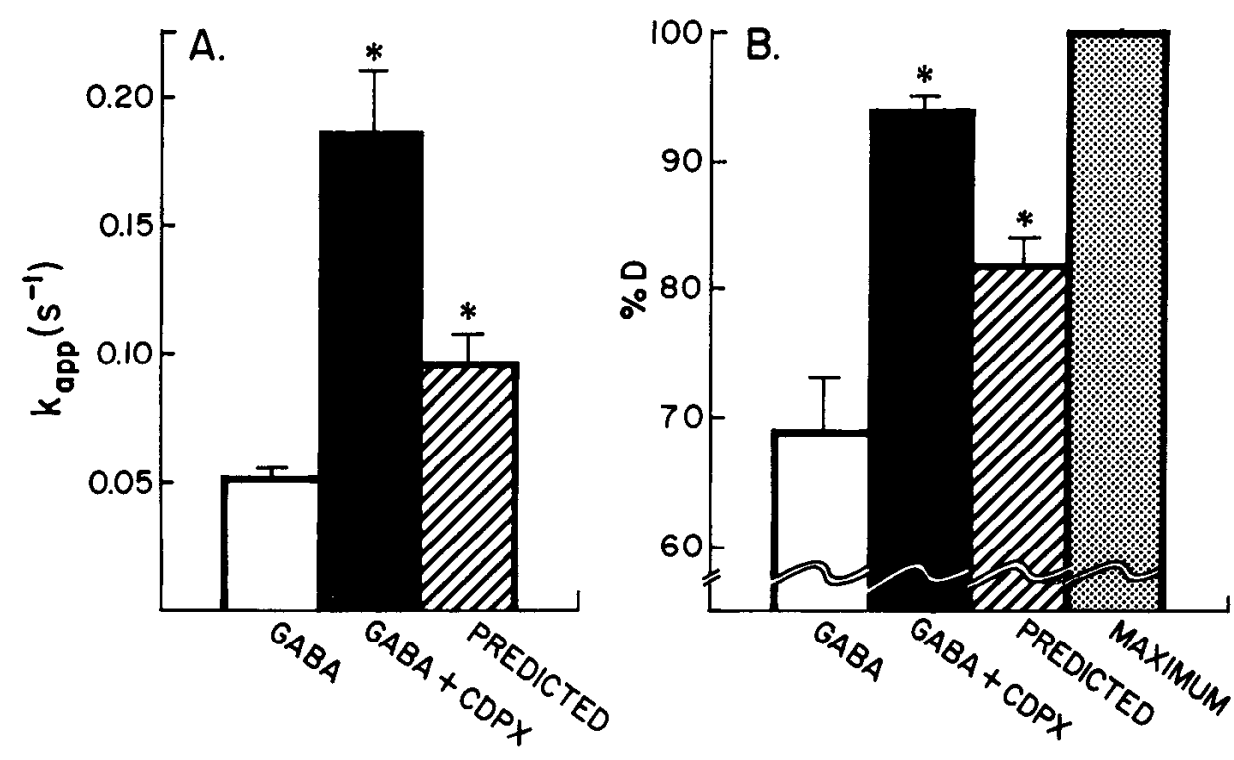


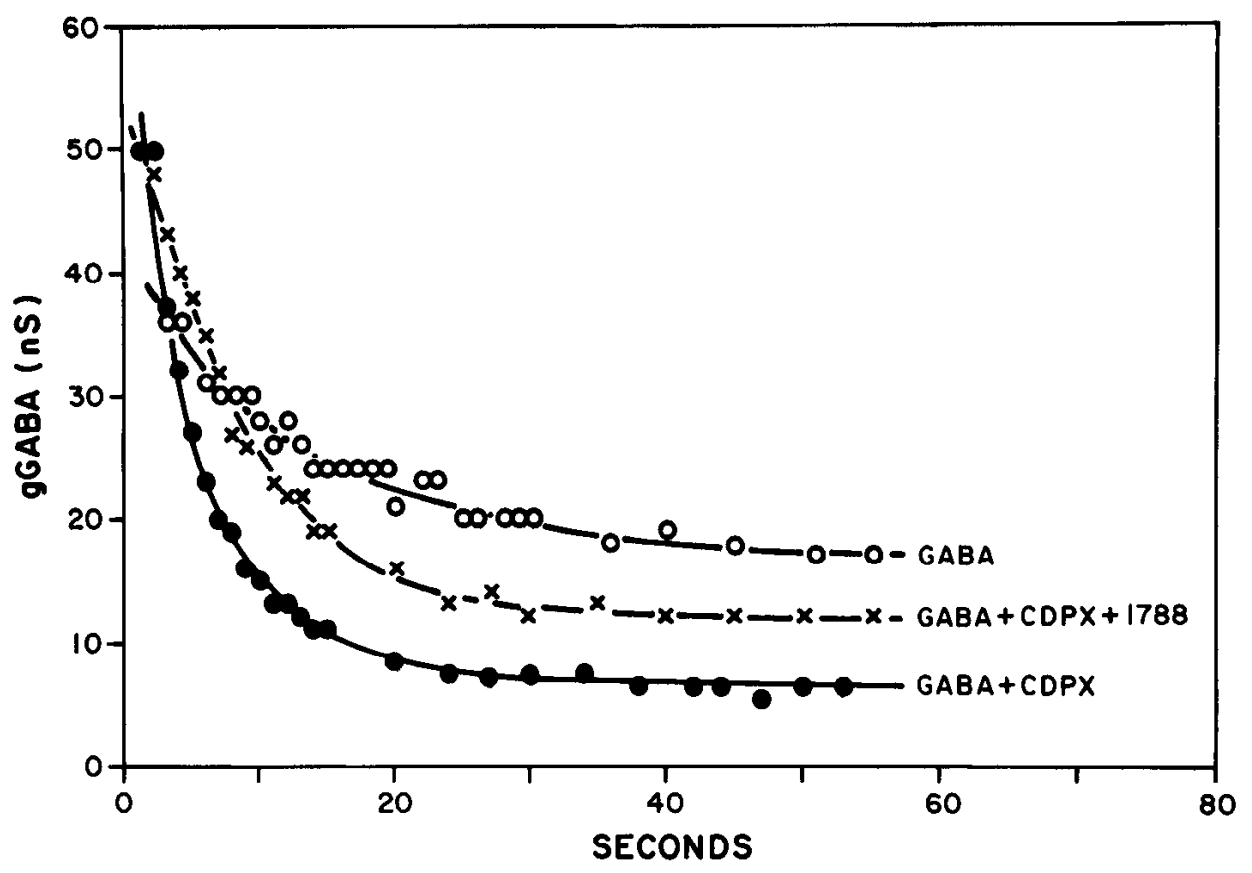

Figure 6. Ro15-1788 antagonizes CDPX enhancement of GABA-induced desensitization. Time course for desensitization, in a single neuron, to $10 \mu \mathrm{M}$ GABA applied alone (O), in the presence of $300 \mu \mathrm{M}$ CDPX (O), and in the presence of both $300 \mu \mathrm{M}$ CDPX and $2 \mu \mathrm{M} \operatorname{Rol} 5-1788(\times)$. $\% D$ is 53 and $87 \%$, respectively, for GABA and GABA + CDPX, which represents a $64 \%$ increase in the presence of CDPX. $\% D$ for GABA in the presence of CDPX +1788 is $75 \%$, representing a $42 \%$ increase over that for GABA alone. Thus, the presence of Rol5-1788 reduces CDPX enhancement by $34 \%$ [1 $(42 \% / 64 \%) \times 100 \%]$. Furthermore, Ro15-1788 reduces CDPX enhancement of $k_{\text {app }}$ by $46 \%$. Similar values were obtained in another neuron. The data shown are from consecutive applications to a single neuron. With regard to pcak response, this sequence was repeated twice on this cell and the results, together with data from another cell, demonstrate that the presence of Ro151788 reduces the peak response of GABA + CDPX to within that for GABA alone. increased receptor occupancy by GABA in the presence of CDPX, but rather indicates that the kinetics of desensitization are specifically altered.

The finding that Ro15-1788 antagonizes CDPX stimulation of desensitization suggests that the benzodiazepine receptor mediates this effect. Biochemical (Mohler and Richards, 1981) and electrophysiological (Chan and Farb, 1985) studies, respectively, have shown that Rol5-1788 binds to the benzodiazepine receptor, but behaves as a weak partial agonist. Analogously, Ro15-1788 could possess weak intrinsic activity as a modulator of desensitization. This may account for the small enhancement of $\% D$ by Ro 15-1788 alone. The ability of Ro15-1788 to antagonize CDPX stimulation of desensitization indicates that (1) CDPX is not exerting its effect via a channel-block mechanism, and (2) benzodiazepine receptor occupancy alone is insufficient to produce stimulation of GABA receptor desensitization. Significantly, the results strongly suggest that stimulation of desensitization depends on the efficacy of the ligand bound to the benzodiazepine receptor.

The general agreement between results obtained from $\mathrm{KCl}$ and KAc recordings indicates that the depolarization seen in $\mathrm{KCl}$ recordings is not confounding or generating the findings presented. One possible exception to this is the greater $\% D$ value for $10 \mu \mathrm{M}$ GABA seen with $\mathrm{KCl}$ electrodes (Table 1). This may be related to depolarization if peak $g_{\mathrm{GAAA}}$ is being overestimated due to a contribution from increased potassium conductance activated by depolarization.

The mechanism for the stimulation of desensitization remains to be elucidated. It seems likely, however, that CDPX binds to the benzodiazepine site with higher affinity when the GABA receptor is desensitized. GABA is known to enhance benzodiazepine binding to cortical membranes (Briley and Langer, 1978; Tallman et al., 1978). These in vitro studies are performed at equilibrium, a condition under which the GABA receptor is expected to be desensitized $(>20 \mathrm{~min}$ incubation time for
GABA). This suggests that benzodiazepines have a higher affinity for binding when the GABA receptor is desensitized (Farb et al., 1984). The stimulation of desensitization described here is consistent with this prediction. By stabilizing the desensitized GABA receptor, benzodiazepines would be expected to increase the extent of desensitization. If GABA receptor desensitization proceeds and recovers via isomerization events, as proposed for the acetylcholine receptor, then a stabilization of the desensitized state would be accompanied by either an increase in the rate of onset for desensitization, a decrease in the rate of recovery from desensitization, or both. The enhancement of $k_{\mathrm{app}}$, therefore, provides support for this model.

An earlier report (Choi et al., 1981) showed that the ability of CDPX to potentiate $g_{\mathrm{GABA}}$ in chick spinal cord cultures is unaffected by a $2 \mathrm{hr}$ exposure to CDPX. This indicates that the CDPX effect does not desensitize and, importantly, that CDPX does not directly desensitize the GABA response. Taken together, the results support a model consistent with the synergistic action of CDPX and GABA on desensitization of the GABA receptor.

Thus, the results demonstrate that GABA action is modulated by benzodiazepines at 2 levels: (1) stimulation of GABA receptor desensitization, and (2) potentiation of the pcak response to GABA. At present, a physiological role for the stimulation of desensitization is unclear. The involvement of densitization in control of synaptic efficacy during persistent neurotransmitter action, or as a cellular control mechanism (perhaps requiring the activation of a second messenger), presents attractive possibilities and will require further investigation. We speculate that this rapid stimulation of desensitization may trigger the onset of persistent subsensitivity of the GABA receptor to enhancement by benzodiazepines during chronic exposure to diazepam (Gonsalves and Gallager, 1985). It is interesting that modulation of desensitization does not appear to be restricted to the GABA receptor complex. At the nicotinic acetylcholine 
receptor, substance $\mathbf{P}$ is thought to enhance desensitization (Clapham and Neher, 1984), although, in striking contrast to the action of CDPX at the GABA receptor, substance $P$ enhancement of desensitization is associated with a decrease in the amplitude of the peak response to acetylcholine. The occurrence of stimulation of desensitization in 2 separate transmitter systems suggests that this phenomenon may represent an important mechanism of action for neuromodulation at neurotransmitter receptors in general.

\section{References}

Briley, M. S., and S. Z. Langer (1978) Influence of GABA receptor agonists and antagonists on the binding of ${ }^{3} \mathrm{H}$-diazepam to the benzodiazepine receptor. Eur. J. Pharmacol. 52: 129-132.

Chan, C. Y., and D. H. Farb (1985) Modulation of neurotransmitter action: Control of the $\gamma$-aminobutyric acid response through the benzodiazepine receptor. J. Neurosci. 5: 2365-2373.

Choi, D. W., D. H. Farb, and G. D. Fischbach (1977) Chlordiazepoxide selectively augments GABA action in spinal cord cell cultures. Nature 269: 342-344.

Choi, D. W., D. H. Farb, and G. D. Fischbach (1981) Chlordiazepoxide selectively potentiates GABA conductance of spinal cord and sensory neurons in cell culture. J. Neurophysiol. 45: 621-631.

Clapham, D. E., and E. Neher (1984) Substance P reduces acetylcholine-induced currents in isolated bovine chromaffin cells. J. Physiol. (Lond.) 347: 255-277.

Costa, E., A. Guidotti, and C. C. Mao (1975) Evidence for involvement of GABA in the action of benzodiazepines: Studies on rat cerebellum.
In Mechanism of Action of Benzodiazepines, E. Costa and P. Greengard, eds., pp. 113-130, Kaven, New York.

Farb, D. H., D. K. Berg, and G. D. Fischbach (1979) Uptake and release of [ ${ }^{3} \mathrm{H}$ ]gamma-aminobutyric acid by embryonic spinal cord neurons in dissociated cell culture. J. Cell Biol. 80: 651-661.

Farb, D. H., L. A. Borden, C. Y. Chan, C. M. Czajkowski, T. T. Gibbs, and G. D. Schiller (1984) Modulation of neuronal function through benzodiazepine receptors: Biochemical and electrophysiological studies on neurons in primary monolayer cell culture. Ann. NY Acad. Sci. 435: 1-31.

Gonsalves, S. F., and D. W. Gallager (1985) Spontaneous and Ro 15 1788-induced reversal of subsensitivity to GABA following chronic benzodiazepines. Eur. J. Pharmacol. 110: 163-170.

Haefely, W. (1984) Actions and interactions of benzodiazepine agonists and antagonists at GABAergic synapses. In Actions and Interactions of $G A B A$ and Benzodiazepines, N. G. Bowery, ed., pp. 263285, Raven, New York.

Levitzki, A. (1986) Bacterial adaptation, visual adaptation, receptor desensitization-a common link? Trends Pharmacol. Sci. 7: 3-6.

Mierlak, D., and D. H. Farb (1985) Chlordiazepoxide stimulates desensitization of the GABA response. Soc. Neurosci. Abstr. 11: 277.

Mohler, H., and J. G. Richards (1981) Agonist and antagonist benzodiazepine receptor interaction in vitro. Nature 294: 763-765.

Olsen, R. W. (1982) Drug interactions at the GABA receptor-ionophore complex. Annu. Rev. Pharmacol. Toxicol. 22: 245-277.

Study, R. E., and J. L. Barker (1981) Diazepam and (-)-pentobarbital: Fluctuation analysis reveals different mechanisms for potentiation of $\gamma$-aminobutyric acid responses in cultured central neurons. Proc. Natl. Acad. Sci. USA 78: 7180-7184.

I'allman, J. F., J. W. Thomas, and D. W. Gallager (1978) GABAergic modulation of benzodiazepine binding site sensitivity. Nature 274 : 383-385. 